\title{
Double-blind Cross-over Study of Ketoprofen and Ibuprofen in Management of Rheumatoid Arthritis
}

\author{
SARAH B. MILLS, M. BLOCH， F. E. BRUCKNER
}

British Medical fournal, 1973, 4, 82-84

\section{Summary}

A double-blind cross-over study of ketoprofen (Orudis) $150 \mathrm{mg}$ daily and ibuprofen (Brufen) $1,200 \mathrm{mg}$ daily was carried out in 35 outpatients with rheumatoid arthritis. Results suggest that analgesic and anti-inflammatory activity of ketoprofen is superior to that of ibuprofen. Significantly greater pain relief $(P<0.05)$ and reduction in joint circumference $(P<0.01)$ was obtained with ketoprofen than with ibuprofen. Side effects of the drugs were comparable and pot serious.

\section{Introduction}

Ketoprofen (Orudis), 2-(3-benzoylphenyl) propionic acid, is a new non-steroidal analgesic and anti-inflammatory agent, with a structure that bears a superficial similarity to the anti-inflammatory agent ibuprofen (Brufen), in that it has a $\beta$-phenylpropionic group.

It has been shown to have potent analgesic, anti-inflammatory, and antibradykinin activities in studies in laboratory animals (Julou et al., 1971).

Recent clinical studies have shown that ketoprofen is well tolerated by patients and has a low incidence of adverse reactions (G. Gomez, personal communication, 1972; D. W. Zutshi and R. M. Mason, personal communication, 1972).

In double-blind cross-over studies ketoprofen has been found to have significant analgesic and anti-inflammatory activity compared with placebo (Cathcart et al., 1973; Zutshi et al., 1973), and to have comparable therapeutic efficacy with indomethacin when given in equal dosage (Gyory et al., 1972) in patients with rheumatoid arthritis and osteoarthrosis of the hip.

Ibuprofen has been claimed as a useful analgesic and antiinflammatory agent; it is significantly less potent than indomethacin but has a lower incidence of side effects (OwenSmith and Burry, 1972; Hart, 1972).

The present study was designed to compare the analgesic and anti-inflammatory activities and side effects of ketoprofen and ibuprofen in patients with rheumatoid arthritis.

\section{Department of Physical Medicine, St. George's Hospital, London SW17 0QT \\ SARAH B. MILLS, B.M., B.CH., Research Registrar \\ F. E. BRUCKNER, M.B., M.R.C.P., Consultant in Physical Medicine}

May \& Baker Ltd., Dagenham, Essex

M. BLOCH, M.D., Medical Adviser (Present address: Smith, Kline and French Laboratories, Ltd., Welwyn Garden City, Herts.)

\section{Patients and Methods}

Thirty-five outpatients who satisfied the American Rheumatism Association criteria for definite or classical rheumatoid arthritis (Ropes et al., 1959) were admitted to the trial (table I). All had evidence of joint inflammation and involvement of at least two proximal interphalangeal joints of the hands. Informed consent was obtained from patients, and their general practitioners were notified before the start of the trial.

Patients excluded were those who had received corticosteroids or antimalarial or immunosuppressive drugs during the previous three months; patients with a history of gastrointestinal, renal, or hepatic disease; women of child-bearing age (except one aged 42 years who had had a hysterectomy); and children. Patients satisfactorily stabilized on gold therapy were not excluded from the trial.

A double-blind cross-over technique was used, patients receiving two weeks' treatment of each trial drug in turn with the sequence determined by random allocation. The drugs were supplied in capsules of identical appearance containing either $25 \mathrm{mg}$ ketoprofen or $200 \mathrm{mg}$ ibuprofen, and patients were instructed to take two capsules three times a day with meals. Patients were also supplied with a known number of paracetamol tablets, $500 \mathrm{mg}$, to be used only for the control of severe pain. All unused capsules and paracetamol tablets were returned for counting. All other anti-inflammatory and analgesic treatment was stopped at the time of the initial assessment.

Patients were assessed on the first day of the trial, at two weeks, and at four weeks, by the same independent observer, at the same time of day for each patient.

Laboratory investigations included a full blood count, erythrocite sedimentation rate (E.S.R.), standard liver function tests, and measurement of plasma proteins.

Subjective assessments were based on answers to standard questions.

Severity of pain (nil, slight, moderate, severe, very severe) and current clinical state (very good, good, fair, poor, very poor) were scored on a five-point scale grading severity of symptoms from 0 to 4. Duration of morning stiffness was recorded for quarter-hour intervals up to four hours, based on a 0 to 15 scale.

Side effects were noted in response to the standard question, "Has the treatment upset you in any way during the past week? If yes, in what way ?" At the final assessment patients were asked to state a preference for the first or second fortnight of the treatment.

Objective assessments were of (a) grip strength-taken as the maximum of three readings made with each hand, and measured with a grip dynamometer attached to a sphygmomanometer and inflated to $30 \mathrm{~mm} \mathrm{Hg}$; (b) Joint circumference-at the initial assessment the two proximal interphalangeal joints showing most signs of inflammation were chosen. These were measured on each occasion, using the Geigy instrument, and the mean of two readings for each joint was taken; and (c) E.S.R., which was

TABLE I-Details of $34^{*}$ Patients who Completed Study

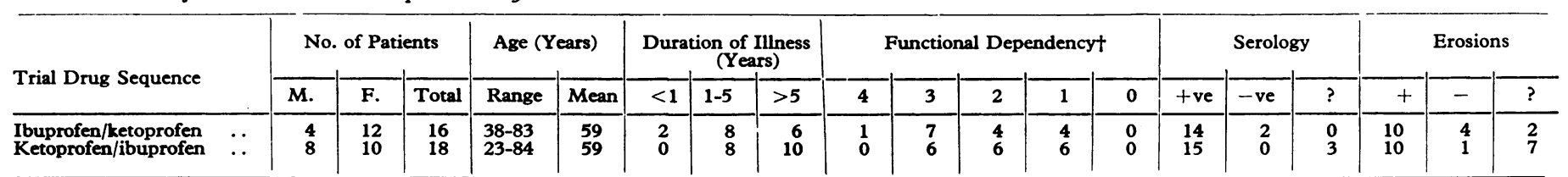

- One additional patient aged 84 died from concurrent disease, making a total of 35 patients admitted to the study.

+ Modified after Steinbrocker et al. (1949), grade II being subdivided into two categories of severity of disability. 
TABLE II-Subjective Assessments in 34 Patients Completing Study

\begin{tabular}{l|c|c|c|c|c}
\hline & $\begin{array}{c}\text { No } \\
\text { Change }\end{array}$ & Uncertain & $\begin{array}{c}\text { Ketoprofen } \\
\text { Favoured }\end{array}$ & $\begin{array}{c}\text { Ibuprofen } \\
\text { Favoured }\end{array}$ & $\begin{array}{c}\text { P } \\
\text { Value }\end{array}$ \\
\hline $\begin{array}{l}\text { Severity of pain .. } \\
\text { Duration of morning } \\
\text { stiffness . }\end{array}$ & 17 & 0 & 13 & 4 & $<0.05$ \\
$\begin{array}{l}\text { Current clinical state } \\
\text { Drug preference .. }\end{array}$ & 14 & 0 & 12 & 8 & N.S. \\
\hline
\end{tabular}

N.S. $=$ Not significant.

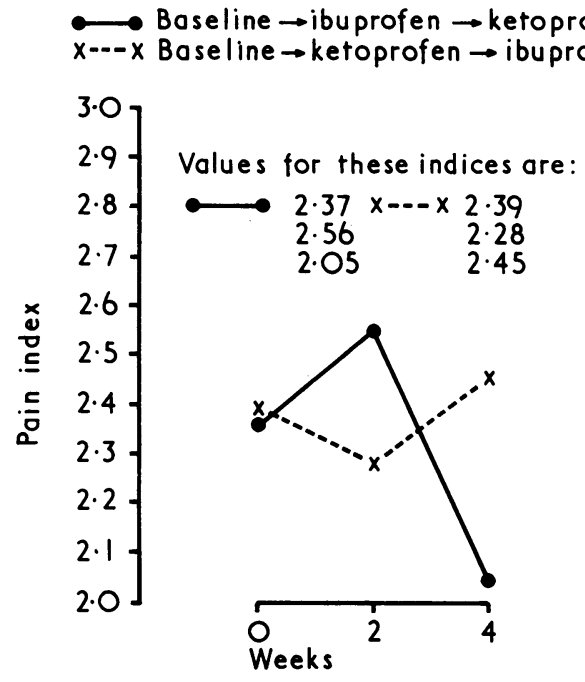

FIG. 1-Effect of treatment on severity of pain.

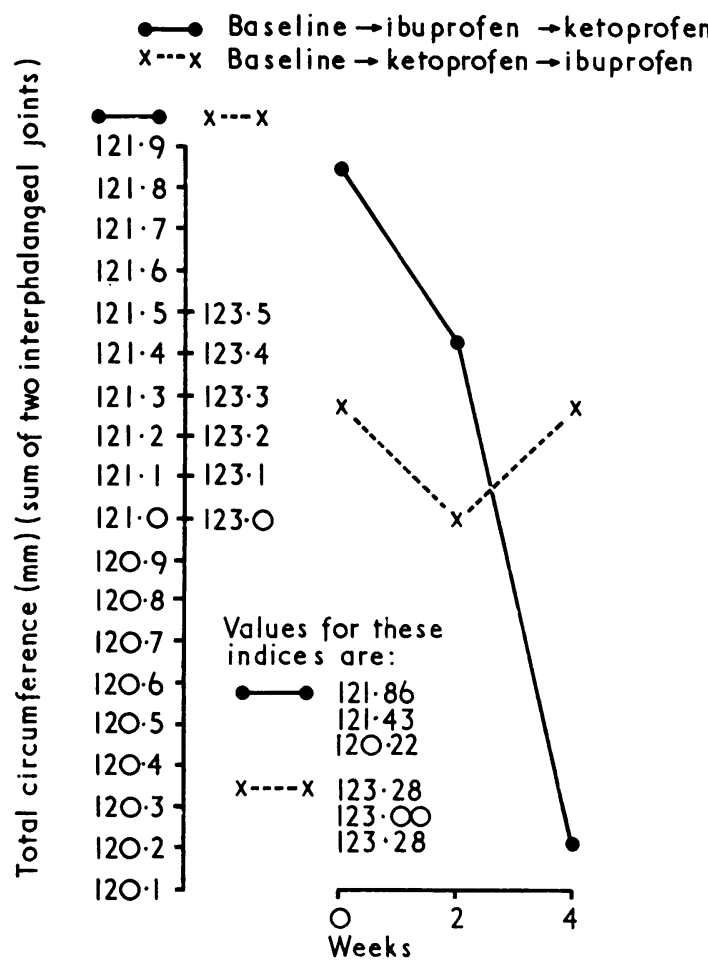

FIG. 2-Effect of treatment on joint circumference. measured at each visit by the Westergren method by the same observer.

The difference between the number of paracetamol tablets taken with each drug (the rescue drug count) provided an indirect comparison of the analgesic activity of the two drugs.

\section{Results}

Thirty-four patients completed the trial (table I). One woman aged 84 years died from thyrotoxic atrial fibrillation leading to a cerebral embolus in the first week of treatment with ibuprofen.

Statistically significant values favouring ketoprofen were obtained for pain relief $(P=<0.05)$, and reduction of joint circumference $(P=<0.01)$, reflecting analgesic and antiinflammatory activity respectively (tables II and III). A crossover effect of ketoprofen and ibuprofen for these two factors is clearly shown in figs. 1 and 2 . There was, additionally, a trend in favour of ketoprofen in respect of morning stiffness, and grip strength, and in the rescue drug index (table IV).

There was a trend in favour of ibuprofen in assessment of current clinical state (not significant), and in reduction of E.S.R. $(P<0.05)$.

Adverse reactions (table V) occurred with equal frequency with both drugs. Symptoms of dyspepsia were more frequent with ketoprofen than with ibuprofen. However, none of the symptoms was severe with either drug and in no case necessitated withdrawal of trial medication.

TABLE IV-Difference in Number of Paracetamol Tablets Required between Treatment with Ketoprofen and with Ibuprofen

\begin{tabular}{ll|c|c|c|c|c}
\hline & $\begin{array}{c}\text { No } \\
\text { Change }\end{array}$ & Uncertain & $\begin{array}{c}\text { Ketoprofen } \\
\text { Favoured }\end{array}$ & $\begin{array}{c}\text { Ibuprofen } \\
\text { Favoured }\end{array}$ & $\begin{array}{c}\mathbf{P} \\
\text { Value }\end{array}$ \\
\hline No. of patients &. & 4 & 3 & 16 & 11 & N.S.
\end{tabular}

N.S. $=$ Not significant

TABLE v-Analysis of Symptoms in 34 Patients Completing Study

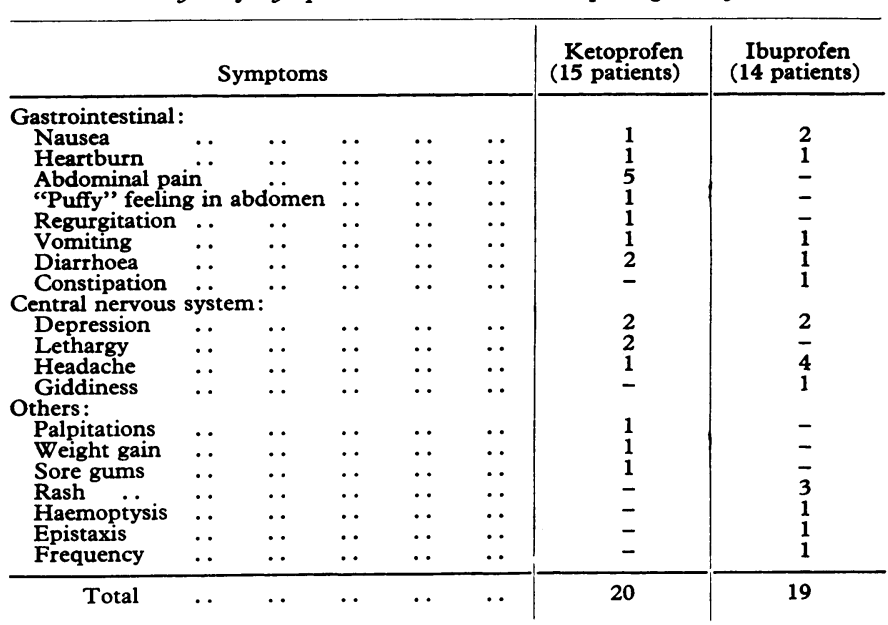

No of patients without symptoms during treatment with ketoprofen, 6 ; ibuprofen, 7 ; bo. of patients without symptoms during treatment with both drugs, 8.

No patients were withdrawn or dropped out from the study. One patient aged 84 died from concurrent disease (thyrotoxicosis, atrial fibrillation, cerebrovascular accident) during treatment with ibuprofen.

TABLE III-Objective Assessment in 34 Patients Completing Study

\begin{tabular}{|c|c|c|c|c|c|c|c|}
\hline & & Ketoprofen & Ibuprofen & Difference & $\begin{array}{c}\text { Standard Error } \\
\text { (S.E.) }\end{array}$ & Difference/S.E. & $\mathrm{P}$ Value \\
\hline 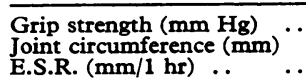 & $\begin{array}{l}. . \\
\cdots \\
\cdots\end{array}$ & $\begin{array}{r}156 \cdot 40 \\
60 \cdot 80 \\
48 \cdot 18\end{array}$ & $\begin{array}{r}149 \cdot 86 \\
61 \cdot 17 \\
44 \cdot 94\end{array}$ & $\begin{array}{r}6 \cdot 54 \\
-0.37 \\
3 \cdot 24\end{array}$ & $\begin{array}{l}4 \cdot 6 \\
0 \cdot 12 \\
1 \cdot 52\end{array}$ & $\begin{array}{l}1 \cdot 4 \\
3 \cdot 0 \\
2 \cdot 13\end{array}$ & $\begin{array}{l}\text { N.S. } \\
<0.01 \\
<0.05\end{array}$ \\
\hline
\end{tabular}

If normal deviate (Difference/S.E.) $>2.6$ then $P<0.01$; if $>2.0$ then $P<0.05$. 


\section{Discussion}

The present study was designed to compare ketoprofen $150 \mathrm{mg}$ daily with ibuprofen $1,200 \mathrm{mg}$ daily in the treatment of rheumatoid arthritis.

Cromie (1963) pointed out that gross alterations in formulations of trial drugs could possibly alter bioavailability, and theoretically the change in presentation of ibuprofen in the present study might have affected its bioavailability and reduced its effectiveness. However, the manufacturers (Boots) thought that the $200 \mathrm{mg}$ capsules of ibuprofen used in this study were suitable for clinical trial purposes.

The results suggest that ketoprofen has analgesic and antiinflammatory activity superior to ibuprofen. It is noted particularly that statistically significant differences in activity, favouring ketoprofen, were obtained even with the comparatively small number of patients used in this study. These results are consistent with those of Owen-Smith and Burry (1972) and Gyory et al. (1972), who showed, respectively, indomethacin $75 \mathrm{mg}$ to have greater activity than ibuprofen $1,200 \mathrm{mg}$, and ketoprofen $100 \mathrm{mg}$ to have comparable activity with indomethacin $100 \mathrm{mg}$.

Cardoe (1969) and Goldberg et al. (1971) reported an overall reduction in E.S.R. in patients with rheumatoid arthritis treated with ibuprofen. The reduction in E.S.R. in the present study favoured ibuprofen $(P<0.05)$, despite the reverse finding for joint circumference.

A factor influencing the therapeutic efficacy of drugs, both in clinical trials and in other clinical situations, is drug interaction. Ketoprofen has been shown to have no effect on hepatic drugmetabolizing enzymes, based on a study of plasma-clearance of antipyrine (Cathcart et al., 1973), and is unlikely therefore to interact with drugs metabolized by the liver.

An important consideration in assessing the value of a new drug for treatment of rheumatoid arthritis is incidence of adverse reactions. A drawback to the use of indomethacin, a powerful analgesic and anti-inflammatory agent, is a relatively high incidence of side effects. Ibuprofen has been found to be better tolerated, but its therapeutic efficacy has been questioned (Hart, 1972; Owen-Smith and Burry, 1972). Previous long-term studies of ketoprofen $150 \mathrm{mg}$ daily have shown that this dose is well tolerated by patients, and is not associated with serious adverse reactions or with significant changes in biological values monitored at monthly intervals for up to 12 months (G. Gomez, personal communication, 1973). These findings are consistent with the present results in which side effects of ketoprofen and ibuprofen were found to be comparable and not serious.

In conclusion, the present study has shown that analgesic and anti-inflammatory activity of ketoprofen is significantly superior to that of ibuprofen, while adverse reactions of the two drugs are comparable and not serious. This is further evidence that ketoprofen may be a useful drug in the clinical management of rheumatoid arthritis.

Requests for reprints should be sent to Dr. F. E. Bruckner.

Ketoprofen will be available in the United Kingdom from next month.

\section{References}

Cardoe, N. (1969). Paper read at the 12th International Congress of Rheumatology, Prague.

Cathcart, B. J., Vince, J. D., Gordon, A. J., Bell, M. A., and Chalmers, I. M. (1973). Annals of the Rheumatic Diseases, 32, 62.

Cromie, B. W. (1963). Lancet, 2,994.

Goldberg, A. A. J., Hall, J. E., Buckler, J. Warwick, Dodsworth, P. G., and Agar, J. (1971). Practitioner, 207, 343.

Gyory, A. N., Bloch, M., Burry, H. C., and Grahame, R. (1972). British Medical fournal, 4, 398.

Hart, F. D. (1972). Practitioner, 208, 10.

Julou, L., et al. (1971). fournal de Pharmacologie, 2, 259

Owen-Smith, B. D., and Burry, H. C. (1972). Rheumatology and Physical Medicine, 2,281 .

Ropes, M. W., Bennett, G. A., Cobb, S., Jacox, R., and Jessar, R. A. (1959). Annals of the Rheumatic Diseases, 18, 49.
.

Steinbrocker, O., Traeger, C. H., and Batterman, R. C. (1949). Fournal of the American Medical Association, 140, 659.

Zutshi, D. W., Marr, S., Bloch, M., and Mason, R. M. (1973). Rheumatology and Rehabilitation, 12, 62.

\title{
Tetracycline-resistant Beta-haemolytic Streptococci in South-west Essex : Decline and Fall
}

\author{
M. H. ROBERTSON
}

British Medical fournal, 1973, 4, 84-85

\section{Summary}

The prevalence of tetracycline-resistant beta-haemolytic streptococci in South-west Essex has been recorded over the past 10 years. It has fallen from a peak of 35\% in 1965 to a level of $9.2 \%$ in 1972. Ear infections no longer provide the highest incidence of these organisms; vaginal, perineal, and skin infections now seem to be of greater relative importance but throat swabs still provide the greatest actual number of isolations. Erythromycinresistant strains are still rare.

St. Margaret's Hospital, Epping, Essex

M. H. ROBERTSON, M.B., M.R.C.PATH., Consultant Bacteriologist

\section{Introduction}

Tetracycline-resistant beta-haemolytic streptococci have often been recorded since 1960 and their incidence in South-west Essex has been monitored since 1963 (Robertson, 1965, 1968). The incidence rose to a peak of $35 \%$ in 1965, remained at $33.5 \%$ in 1966 , and fell slightly to $27 \%$ in 1967 , when it was speculated that the figures might have begun to decline.

Recent reports indicate that the incidence of tetracyclineresistant beta-haemolytic streptococci is indeed falling. A survey of these organisms causing ear, nose, and throat infections in London shows their incidence declining from $42 \%$ in 1967 to $27 \%$ in early 1971 (Rees, 1971). A level of $6 \%$ is recorded in Sweden (Kahlmeter and Kamme, 1972), though no previous figures for Scandinavia ware found by these authors.

We present the figures for South-West Essex from 1968 to 1972. The methods of isolation and sensitivity testing were as previously used-that is, organisms were grown on blood agar base No. 2 (Oxoid) or sensitivity test agar (Oxoid) both containing $7 \%$ added horse blood. Antibiotic discs containing $10 \mu \mathrm{g}$ of tetracycline, $10 \mu \mathrm{g}$ of erythromycin, and 1.5 units of penicillin were applied, and the organism was regarded as resistant if it grew right to the edge of the disc on overnight incubation. 